\title{
Statistical Design for Optimization and Determination of Tizanidine Hcl using Folin-Ciocalteu (Fc) as Chromogenic Reagent
}

Permender Rathee ${ }^{1}$, Kamal Dua ${ }^{2}$, Sushila Rathee ${ }^{3}$ and Vikash Kumar ${ }^{3 *}$

${ }^{1}$ Quantum Solutions India, Rajiv Gandhi Technology Park, Chandigarh, India

${ }^{2}$ Department of Pharmaceutical Technology, School of Pharmacy, International Medical University, Kuala Lumpur, Malaysia

${ }^{3} P D$ Memorial College of Pharmacy, Sector-3A, Sarai Aurangabad, Bahadurharh, India

\begin{abstract}
A simple, sensitive spectrophotometric method has been developed for quantitative determination of Tizanidine Hydrochloride in bulk and pharmaceutical formulations with application of factorial design. In this method, Tizanidine Hydrochloride is made to react with Folin-Ciocalteu (FC) reagent under alkaline conditions forming a blue chromogen having absorption maximum at $663 \mathrm{~nm}$. Beer's law was obeyed in the concentration range of 4-36 $\mu \mathrm{g} / \mathrm{ml}$. Results of the analysis were validated as per ICH guidelines and by recovery studies. A 3-factor, 3-level statistical design (Box-Behnken) was used to derive a second-order polynomial equation to construct contour plots for prediction of response. Independent variables studied were the FC-reagent (X1), sodium carbonate (X2) and drug concentration (X3) and the levels of each factor were low, medium, and high. The dependent variable studied was absorbance (Y1). The aims of this study to determination and optimize the Tizanidine $\mathrm{HCl}$ using $\mathrm{FC}$ as Chromogenic reagent; the design demonstrated the role of the derived equation (polynomial) and two dimensional plots in predicting the values of dependent variable for optimization.
\end{abstract}

Keywords: Spectrophotometry; Tizanidine Hydrochloride; FC reagent; Box-Behnken Design

\section{Introduction}

Tizanidine, 5-Chloro-N-(4, 5-dihydro-1H-imidazol-2-yl)-2, 1, 3-benzothiadiazol-4-amine, is a new centrally acting skeletal muscle relaxant [1]. It is a $a 2$ adrenergic agonist [2] which inhibits spinal reflex transmission by descending facilatory pathways and via supraspinal inhibitory effects. In addition to its muscle relaxant properties and central analgesic effect, it also has gastro protective effect. Hence it is used in combination with NSAIDs for the treatment of local pain. A survey of literature revealed that various methods are available for the estimation of Tizanidine Hydrochloride individually as well as simultaneously; these includes HPTLC [3,4], RP-HPLC [5], HPLC [6,7], LC-MS [8], Spectrophotometric methods [9-14] but none of the spectrophotometric methods has optimized the various parameters. Therefore, it was highly desirable to develop a simple and robust analytical method that provides satisfactory stability and good sensitivity to the complex for routine analysis of Tizanidine $\mathrm{HCl}$ in dosage forms by using Folin-Ciocalteu (FC) reagent. The FC reagent has been used as a chromogen for determination of various pharmaceutical agents containing nitrogen [15-21]. The focus of the present study was to optimized the concentration of various reagents spectrophotometrically, involved in the reaction to form colored detectable product by employing 3-factor, 3-level Box-Behnken statistical design, and develop robust and simple spectroscopic method using previously optimized process parameters.

\section{Material and Methods}

Standard Tizanidine $\mathrm{HCl}$ was obtained as gift sample from Jackson Pharmaceuticals Pvt. Ltd., Amritsar (Punjab). FC reagent was procured from Loba Chem. Ltd., Mumbai; Sodium Carbonate was procured from S.D Fine and distilled Water (in house production) was used for making solutions. Tizan (Sun Pharma) and Sirdalud (Novartis) tablets, both containing $2.288 \mathrm{mg}$ of Tizanidine Hydrochloride were procured from local market. All UV spectrophotometric measurements were recorded using Double beam Jasco V-630 UV spectrophotometer
(Jasco V 530, India) with spectral band width of $1.5 \mathrm{~nm}$, wavelength accuracy of $\pm 2 \mathrm{~nm}$ and matched quartz cells of $10 \mathrm{~mm}$ optical path length.

\section{Preparation of standard solution}

A definite amount of Tizanidine $\mathrm{HCl}(10 \mathrm{mg})$ was transferred to a $100 \mathrm{~mL}$ volumetric flask. Sufficient quantity of distilled water was added and the solution was sonicated for $10 \mathrm{~min}$. Finally, the volume was maintained with distilled water to give a final concentration of 100 $\mu \mathrm{g} \mathrm{mL} \mathrm{m}^{-1}$. Different sets of working standards at various concentrations were prepared by appropriate dilution of the stock solution.

\section{Preparation of derivatizing agent}

A working solution of detecting reagent was prepared by dissolving $20 \% \mathrm{w} / \mathrm{v}$ sodium carbonate solution and $2 \mathrm{~N}$ FC reagent diluted with two volumes of distilled water. The solution was freshly prepared on daily basis for each experiment.

\section{Calibration solution for analysis}

Aliquots of $(0.4,0.8,1.2,1.6,2.0,2.4,2.8,3.2$ and $3.6 \mathrm{~mL})$ stock solution were transferred to a $10 \mathrm{~mL}$ of volumetric flask using a micropipette. $3 \mathrm{~mL}$ of reagent solution were added to each flask and heated at $42 \pm 2^{\circ} \mathrm{C}$ for $10 \mathrm{~min}$. Each reaction mixture was cooled at room temperature and the volume was made up to mark with distilled water to give final concentrations of $4,8,12,16,20,24,28,32,36 \mu \mathrm{g}$

*Corresponding author: Vikash Kumar, P D Memorial College of Pharmacy, Sector-3A, Sarai Aurangabad, Bahadurharh, India, Tel: 08901451603; E-mail: vikasruhilo1@gmail.com; kamalpharmacist@gmail.com

Received May 01, 2014; Accepted August 20, 2014; Published August 27, 2014

Citation: Rathee P, Dua K, Rathee S, Kumar V (2014) Statistical Design for Optimization and Determination of Tizanidine Hcl using Folin-Ciocalteu (Fc) as Chromogenic Reagent. Pharm Anal Acta 5: 307. doi:10.4172/2153-2435.1000307

Copyright: @ 2014 Rathee $P$, et al. This is an open-access article distributed under the terms of the Creative Commons Attribution License, which permits unrestricted use, distribution, and reproduction in any medium, provided the original author and source are credited. 
Citation: Rathee P, Dua K, Rathee S, Kumar V (2014) Statistical Design for Optimization and Determination of Tizanidine Hcl using FolinCiocalteu (Fc) as Chromogenic Reagent. Pharm Anal Acta 5: 307. doi:10.4172/2153-2435.1000307

$\mathrm{mL}^{-1}$. The absorbance was measured at $663 \mathrm{~nm}$ against a reagent blank. The calibration curve was constructed by plotting absorbance versus concentration $(\mu \mathrm{g} / \mathrm{ml})$ and correlation coefficient was also measured by taking mean of concentrations measured in triplicates.

\section{Sample solution for determination}

For the analysis of Tizanidine Hydrochloride in tablets, two different commercial brands of $2.288 \mathrm{mg}$ strength (Tizan- Sun Pharma, Sirdalud-Novartis) were taken. Twenty tablets each of Tizan and Sirdalud were weighed and powdered. The tablets powder equivalent to $10 \mathrm{mg}$ of Tizanidine Hydrochloride was accurately weighed for both brands and dissolved volumetrically with $100 \mathrm{~mL}$ of water by heating at $42^{\circ} \mathrm{C}$ to give a concentration of $100 \mu \mathrm{g} \mathrm{mL} \mathrm{m}^{-1}$. The flask was cooled and the sample was filtered using filter paper (Whatmann). The filtrate ( 2.5 $\mathrm{mL}$ ) was transferred to another $10 \mathrm{~mL}$ volumetric flask containing 3 $\mathrm{mL}$ of the reagent solution, heated at $45 \pm 5^{\circ} \mathrm{C}$ for $20 \mathrm{~min}$, volume made up to $10 \mathrm{~mL}$ with distilled water and analyzed three times and a mean of the triplicate measurements was taken

\section{Validation}

Linearity was determined by preparing different concentrations of sample solution $\left(4-36 \mu \mathrm{g} \mathrm{mL} L^{-1}\right)$. The precision of the assay was determined by repeatability (intra-day) and intermediate precision (inter-day). Repeatability was evaluated by assaying samples, at the same concentration and during the same day. The intermediate precision was studied by comparing the assays on different days ( 3 days). Three sample solutions ranging 8,16 and $24 \mu \mathrm{g} \mathrm{mL}^{-1}$ were prepared and analyzed. The accuracy of the method was determined as recovery from $20 \mu \mathrm{g} \mathrm{mL}^{-1}$ standard solution spiked with 80,100 and $120 \%$ extra Tizanidine $\mathrm{HCl}$. Specificity was determined by observing that the placebo samples were free from any interfering substances. Placebo samples were prepared by dissolving expected ingredients other then drugs in equal proportions and then assayed in order to verify that none of the excepients of the tablets interfered with the quantity of drugs. Limit of detection (LOD) and Limit of Quantification were calculated against blank. All solutions were prepared and used in triplicate.

\section{Design}

Box-Behnken statistical design was used to optimize the validation parameters and systemically investigate the effect of wide range of independent and dependent variables. FC reagent concentration (X1), sodium bicarbonate concentration (X2) and drug concentration (X3) were three independent variables (factors) considered in the method development of Tizanidine $\mathrm{HCl}$, while the absorbance was a dependent variable (response). Different concentration ranges for FC reagent (1.0-10.0 ml), $\mathrm{NaHCO}_{3}(1.0-10.0 \mathrm{ml})$ and drug $\left(4-36 \mu \mathrm{gL}^{-1}\right)$ were selected. The process parameters were studied by conducting the 17 runs at different levels of all factors. Data collected for responses in each run were analyzed using Design Expert 7.1 software (Statease, USA) and fitted into a multiple linear regression model.

\section{Results}

\section{Optimization of parameters}

Folin-Ciocalteu reagent [22] is a commonly used agent for the determination of primary amines and amino acids. It reacts with groups of Tizanidine $\mathrm{HCl}$ in the presence of sodium bicarbonate $[23,24]$ to form colored reaction product and it measures the amount of the substance needed to inhibit the oxidation of the reagent [25]. The reaction conditions were optimized on the basis of maximum absorbance by UV-Visible spectrophotometer.
To identify the optimum levels of different process parameters influencing the absorbance, an experimental design of 17 runs containing central points was made according to the Box-Behnken statistical design for three selected parameters. The individual and interactive effects of these process variables were studied by conducting the process at different levels of all factors. All the responses observed in 17 runs were simultaneously fitted to first order-, second order- and quadratic models using Design Expert. It was observed that the best fitted model was the quadratic model (results of experimental data and simulated values are enlisted in Table 1).

\section{Fitting of data to the model}

A three-factor, three-level Box-Behnken statistical experimental design as the RSM requires seventeen experiments. The independent variables and the response for all seventeen experimental runs are given in Table 2. The ranges of Y1 for all batches were 0.200-0.876 respectively. All the responses observed for seventeen formulations were simultaneously fitted to quadratic models using Design Expert ${ }^{\circ}$ (Version 7.1.3, Stat-Ease Inc., and Minneapolis, MN). It was observed that the best-fitted model was quadratic model and the comparative values of $\mathrm{R} 2, \mathrm{SD}$ and $\% \mathrm{CV}$ are given in Table 3 along with the regression equation generated for each response. All statistically significant $(\mathrm{p}<0.05)$ coefficients are included in the equations. A positive value represents an effect that favors the optimization, while a negative value indicates an inverse relationship between the factor and the response. It is evident that all the three independent variables viz. the amount of

\begin{tabular}{|l|c|c|c|}
\hline Factor & \multicolumn{3}{|c|}{ Levels used, Actual (Coded) } \\
\hline & Low (-1) & Medium (0) & High (+1) \\
\hline Independent variables & & & \\
\hline $\mathrm{X} 1=$ FC-reagent $(\mathrm{ml})$ & $1.00(-1)$ & $5.50(0)$ & $10.00(+1)$ \\
\hline $\mathrm{X} 2=$ Sodium carbonate $(\mathrm{ml})$ & $1.00(-1)$ & $5.50(0)$ & $10.00(+1)$ \\
\hline $\mathrm{X} 3=$ Drug concentration $\left(\mu \mathrm{g} \mathrm{ml}^{-1}\right)$ & $4.00(-1)$ & $20.00(0)$ & $36.00(+1)$ \\
\hline Constraints & & & \\
\hline Dependant variables & & & \\
\hline Y1=Absorbance & & \\
\hline $0.200 \leq Y \neg 1 \geq 0.872$ & & \\
\hline
\end{tabular}

Table 1: Variables in Box Behnken design.

\begin{tabular}{|c|c|c|c|c|c|c|}
\hline \multicolumn{2}{|c|}{} & \multicolumn{3}{|c|}{ Independent Variable } & \multicolumn{2}{c|}{ Dependent Variables } \\
\hline Runs & Batches & $\mathbf{X}_{1}$ & $\mathbf{X}_{2}$ & $\mathbf{X}_{3}$ & $\mathbf{Y}_{\text {1(ACTUAL) }}$ & $\mathbf{Y}_{\text {1(PREDICTED) }}$ \\
\hline 1 & B1 & 0 & 1 & -1 & 0.352 & 0.67 \\
\hline 2 & B2 & -1 & -1 & 0 & 0.476 & 0.24 \\
\hline 3 & B3 & 1 & 1 & 0 & 0.621 & 0.25 \\
\hline 4 & B4 & -1 & 1 & 0 & 0.492 & 0.23 \\
\hline 5 & B5 & 1 & -1 & 1 & 0.758 & 0.11 \\
\hline 6 & B6 & 0 & -1 & 1 & 0.675 & 0.67 \\
\hline 7 & B7 & -1 & 0 & -1 & 0.201 & 0.697 \\
\hline 8 & B8 & 1 & -1 & 0 & 0.453 & 0.23 \\
\hline 9 & B9 & 0 & 0 & 0 & 0.432 & 0.67 \\
\hline 10 & B10 & 0 & 0 & 0 & 0.408 & 0.24 \\
\hline 11 & B11 & 0 & 0 & 0 & 0.421 & 0.24 \\
\hline 12 & B12 & 0 & 1 & 1 & 0.871 & 0.16 \\
\hline 13 & B13 & 0 & -1 & -1 & 0.286 & 0.23 \\
\hline 14 & B14 & 0 & 0 & 0 & 0.465 & 0.24 \\
\hline 15 & B15 & -1 & 0 & 1 & 0.568 & 0.11 \\
\hline 16 & B16 & -1 & -1 & 0 & 0.432 & 0.16 \\
\hline 17 & B17 & 1 & 0 & -1 & 0.253 & 0.20 \\
\hline & & & & & & \\
\hline
\end{tabular}

Table 2: $\mathrm{X}_{1}=\mathrm{FC}$ Reagent $(\mathrm{ml}) \quad \mathrm{X}_{2}=$ Sodium carbonate $(\mathrm{ml}) \quad \mathrm{X}_{3}=$ Drug Conc. $(\mu \mathrm{g}$ $\left.\mathrm{ml}^{-1}\right) \mathrm{Y}_{1}=$ Absorbance. 
Citation: Rathee P, Dua K, Rathee S, Kumar V (2014) Statistical Design for Optimization and Determination of Tizanidine Hcl using FolinCiocalteu (Fc) as Chromogenic Reagent. Pharm Anal Acta 5: 307. doi:10.4172/2153-2435.1000307

Page 3 of 5

\begin{tabular}{|l|l|l|l|l|l|}
\hline Quadratic model & $\mathbf{R}^{2}$ & Adjusted R & Predicted R & SD & $\%$ CV \\
\hline Response $\left(Y_{1}\right)$ & 0.9898 & 0.9898 & 0.9768 & 0.027 & 5.58 \\
\hline $\begin{array}{l}\text { Regression equations of the fitted quadratic model } \\
Y_{1}=0.34+0.044 X_{1}+0.056 X_{2}+0.22 X_{3}+0.038 X_{1} X_{2}+0.035 X_{1} X_{3+} 0.032 X_{2} X_{3}+0.011 X_{1}{ }^{2}+0 \\
.090 X_{2}^{2}+0.024 X_{3}^{2}\end{array}$ \\
\hline
\end{tabular}

Table 3: Summary of results of regression analysis for response $Y_{1}$ for fitting to quadratic model.

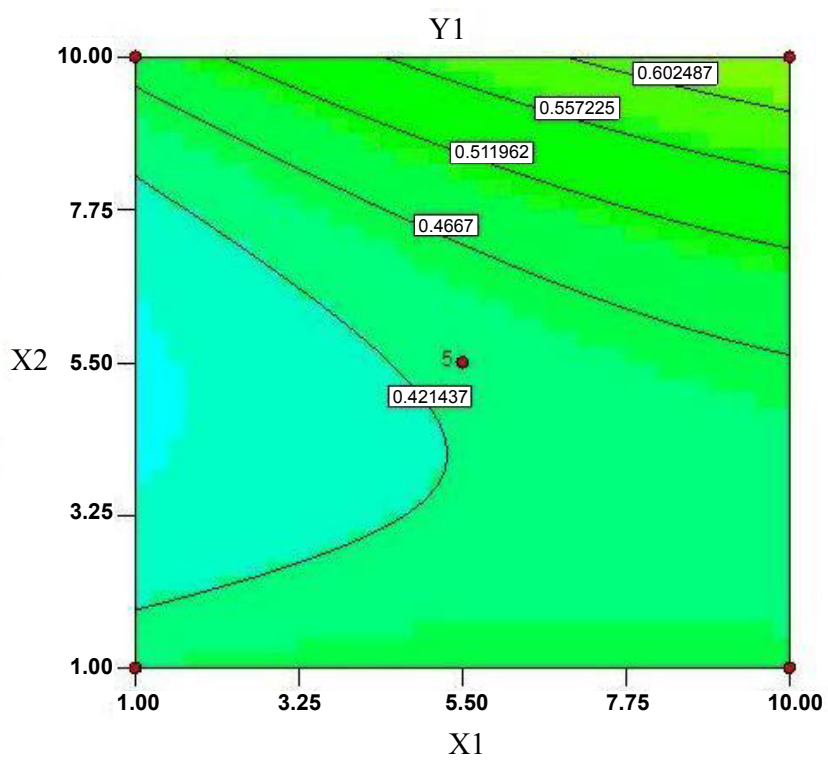

Figure 1a: Contour plot showing the effect of amount of FC-reagent $\left(\mathrm{X}_{1}\right)$ and sodium carbonate $\left(\mathrm{X}_{2}\right)$ on response $\left(\mathrm{Y}_{1}\right)$.

FC-reagent (X1), sodium carbonate (X2) and drug concentration (X3) has interactive effects on the response viz. Y1.

\section{Polynomial Equations Analysis}

The model proposes the following polynomial equation for Absorption

$Y_{1}=0.34+0.044 X_{1}+0.056 X_{2}+0.22 X_{3}+0.038 X_{1} X_{2}+0.035 X_{1} X_{3}+0.032 X_{2}$ $X_{3}+0.011 X_{1}^{2}+0.090 X_{2}^{2}+0.024 X_{3}^{2}$

Where $Y_{1}$ is absorbance, $X_{1}$ is FC-reagent, $X_{2}$ is sodium carbonate and $\mathrm{X}_{3}$ is the concentration of drug. The Model F-value of 75.70 implies the model is significant $(\mathrm{P}<0.0001)$. The "Lack of Fit F-value" of 2.42 implies the Lack of Fit is not significant $(\mathrm{P}=0.2068)$. In this case $\mathrm{X}_{1}$, $\mathrm{X}_{2}, \mathrm{X}_{3}, \mathrm{X}_{1} \mathrm{X}_{2}, \mathrm{X}_{1} \mathrm{X}_{3}, \mathrm{X}_{2} \mathrm{X}_{3}, \mathrm{X}_{2}^{2}$ are significant model terms and $\mathrm{X}_{1} \mathrm{X}_{3}$ and $\mathrm{X}_{2} \mathrm{X}_{3}$ had a more pronounced effect on absorption than any other parameters. The "Pred R-Squared" of 0.8895 is in reasonable agreement with the "Adj R-Squared" of 0.9768. "Adeq Precision" measures the signal to noise ratio. A ratio greater than 4 is desirable. A ratio of 31.319 indicates an adequate signal.

Therefore this model can be used to navigate the design space. The $2 \mathrm{D}$ plots showed the effect of different independent variables on absorbance $\left(\mathrm{Y}_{1}\right)$.

\section{Plots analysis}

Two dimensional contour plots were prepared for the response (Y1) and are shown in Figure 1a-c respectively. The plots are known to study the interaction effects of the factors on the response as well as these plots are utile in studying the effects of two factors on the response at one time. Interactive effect of $\mathrm{X}_{1} \mathrm{X}_{2}$ showed that absorbance increased with increasing concentration of either FC-reagent or $\mathrm{NaHCO}_{3}$ at constant level. Figure $1 \mathrm{~b}$ shows that increase in drug concentration (X3) from 4 to $36\left(\mu \mathrm{g} \mathrm{mL}^{-1}\right)$ enhances the absorbance $\left(\mathrm{Y}_{1}\right)$ from 0.078 to 0.908 with the concentration of FC-reagent $\left(\mathrm{X}_{1}\right)$. Also the interactive effect of $\mathrm{X}_{2}$ and $\mathrm{X}_{3}$ were observed and absorbance was found to increase with increasing the concentration of either drug or sodium carbonate (Figure 1c).

\section{Method validation}

Using the above-optimized parameters, absorption spectra in the range $(200-600 \mathrm{~nm})$ were obtained for the Tizanidine $\mathrm{HCl}$. Linear regression equation was $y=0.0239 \times-0.0591$ with mean correlation coefficient of 0.9994 . Accordingly, the precision of the method was determined satisfactorily. The RSD for intra- and inter-day precision were in the range of $0.139-0.513 \%$ and $0.141-0.987 \%$, respectively. The average recovery of the proposed spectrophotometric method was $98.5 \%$ ( $R S D=0.57 \%$, SEM=0.119). The method was found to be specific as placebo samples did not exhibit any absorption under the experimental conditions. LOD and LOQ were found to be 0.207 and $0.627 \mu \mathrm{g} \mathrm{mL}^{-1}$, respectively. All the measurements were taken in triplicate and mean of readings were used.

\section{Recovery studies}

Recovery studies were carried (I.C.H Q2B guidelines) out by adding 1, 2 and $3 \mathrm{mg}$ of drug to different samples of tablet powder containing the equivalent of $10 \mathrm{mg}$ of drug. From the amount found, percentage recovery was calculated. Precision of the method was studied by carrying out intraday, interday analysis and expressed as $\%$ Relative Standard Deviation. The results of recovery studies were found to be satisfactory and are reported in Table 4 .

\section{Discussion}

The mixed acid in the $\mathrm{FC}$ reagent involves the following chemical species; $3 \mathrm{H}_{2} \mathrm{O} \cdot \mathrm{P}_{2} \mathrm{O}_{5} \cdot 13 \mathrm{WO}_{3} \cdot 5 \mathrm{MoO}_{3} \cdot 10 \mathrm{H}_{2} \mathrm{O}$ and $3 \mathrm{H}_{2} \mathrm{O}$.

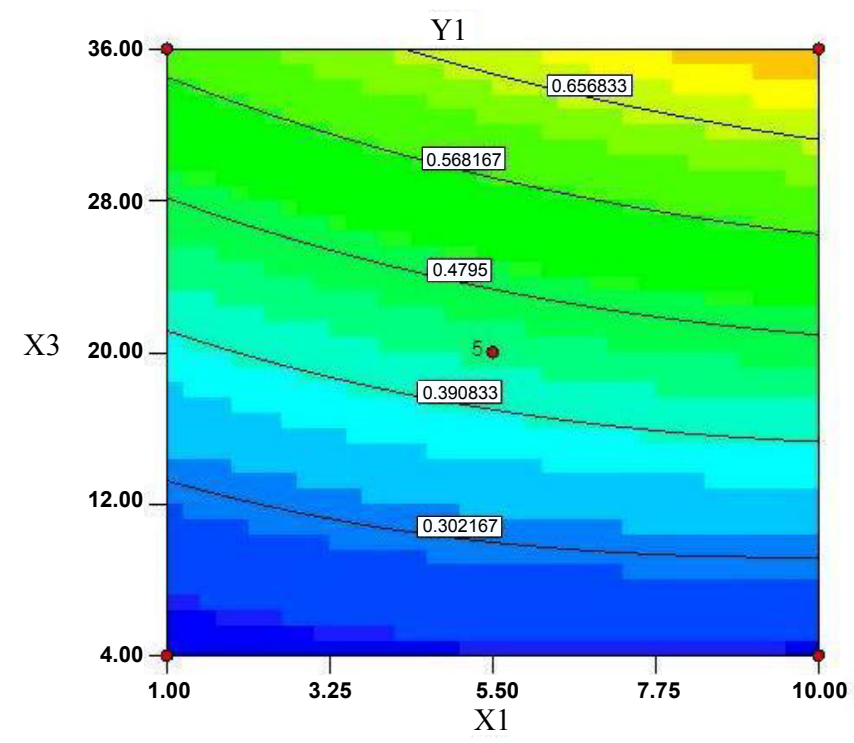

Figure 1b: Contour plot showing the effect of amount of FC-reagent $\left(\mathrm{X}_{1}\right)$ and drug concentration $\left(\mathrm{X}_{3}\right)$ on response $\left(\mathrm{Y}_{1}\right)$. 
Citation: Rathee P, Dua K, Rathee S, Kumar V (2014) Statistical Design for Optimization and Determination of Tizanidine Hcl using FolinCiocalteu (Fc) as Chromogenic Reagent. Pharm Anal Acta 5: 307. doi:10.4172/2153-2435.1000307

Page 4 of 5

\begin{tabular}{|l|c|c|c|c|}
\hline Brand & Labeled amount & Amount found $^{\mathrm{a}}$ & \%Labeled amount & \% RSD \\
\hline Tizan & 2.288 & $2.2732 \pm 0.0048$ & $99.355 \pm 0.2631$ & 0.2648 \\
\hline Sirdalud & 2.288 & $2.2742 \pm 0.0043$ & $99.399 \pm 0.3373$ & 0.3394 \\
\hline
\end{tabular}

a: Average of Four Readings

Table 4: Results of estimation of Tizanidine Hydrochloride in Tablet dosage forms.

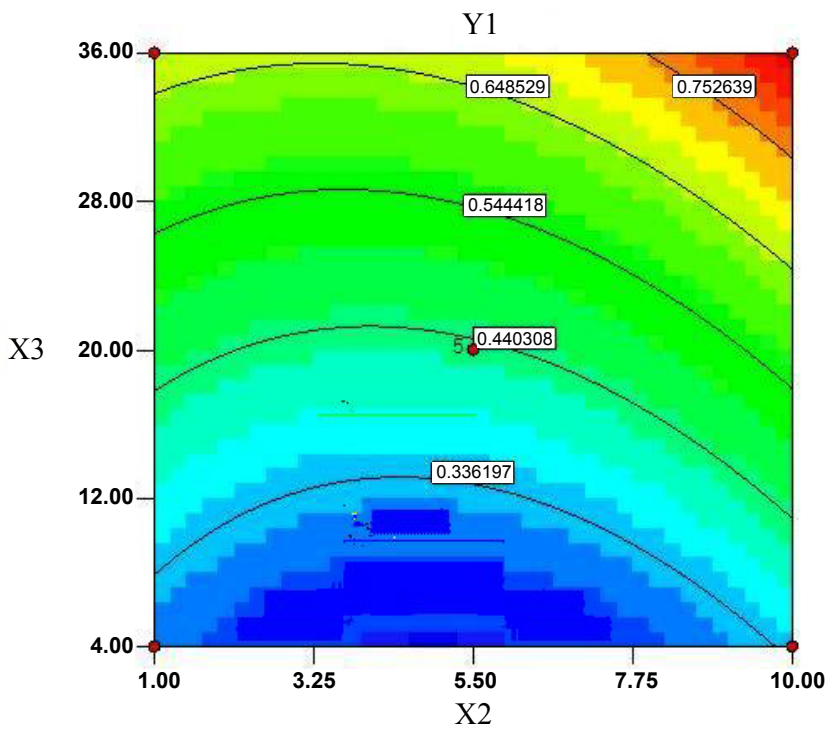

Figure 1c: Contour plot showing the effect of amount of sodium carbonate $\left(\mathrm{X}_{2}\right)$ and drug concentration $\left(\mathrm{X}_{3}\right)$ on response $\left(\mathrm{Y}_{1}\right)$.

$\mathrm{P}_{2} \mathrm{O}_{5} \cdot 14 \mathrm{WO}_{3} \cdot 4 \mathrm{MoO}_{3} \cdot 10 \mathrm{H}_{2} \mathrm{O}$. Tizanidine Hydrochloride probably affects the reduction of 1,2 , or 3 oxygen atoms from tungstate and / or molybdate in FC reagent (Phosphomolybdo tungstate), thereby producing one or more of the possible reduced species which have an intense blue color [22]. The proposed method for determination of Tizanidine Hydrochloride showed molar absorptivity of $5.642 \times 10^{3}$ litre mole $\mathrm{cm}^{-1}$ and Sandell's sensitivity of $0.0514 \mu \mathrm{g} / \mathrm{cm}^{2} / 0.001$ absorbance units. Linear regression of absorbance on concentration gave the equation $y=0.0239 \times-0.0591$ with a correlation coefficient $(r)$ of 0.9994 . Percent relative standard deviation for intraday and interday analysis was found to be 0.741 and 0.645 respectively. Limit of detection and limit of quantitation were found to be 0.207 and 0.627 respectively. The higher percentage recovery value indicates that there is no interference of the excipients present in the formulation. This method is useful for the determination of Tizanidine Hydrochloride in bulk and pharmaceutical formulations.

\section{Concluding Remarks}

Tizanidine $\mathrm{HCl}$ can be determined in pharmaceutical tablets based on reaction with FC reagent in the presence of sodium bicarbonate. Simplicity, accuracy and rapidness are a most attractive advantage of proposed method. The results obtained confirm the optimization and suitability of the proposed methods for the precise analysis and of Tizanidine $\mathrm{HCl}$ in quality control laboratories.

\section{Acknowledgement}

The authors are thankful to Jackson Pharmaceutical Pvt. Ltd., Amritsar, India, for providing gift sample of Tizanidine Hydrochloride and Management of PDM group of institutes (PDM College of Pharmacy), Sarai Aurangabad, Bahadurgarh (Hry.), India for support and providing the facilities to carry out the research work.

\section{References}

1. (2008) Acorda Therapeutics. Inc. Zanaflex (tizanidine hydrochloride) capsules and tablets prescribing information. Hawthorne, New-york.

2. Wagstaff AJ, Bryson HM (1997) Tizanidine. A review of its pharmacology, clinical efficacy and tolerability in the management of spasticity associated with cerebral and spinal disorders. Drugs 53: 435-452.

3. Pawar UD, Sulebhavikar AV, Naik AV, Pingale SG, Mangaonkar KV (2009) Simultaneous Determination of Rofecoxib and Tizanidine by HPTLC. E-Journal Chem 6: 295-302.

4. Mahadik KR, Paradkar AR, Agrawal H, Kaul N (2003) Stability-indicating HPTLC determination of tizanidine hydrochloride in bulk drug and pharmaceutical formulations. J Pharm Biomed Anal 33: 545-552.

5. Nimje H, Wate SP, Dharkar DP, Razdan R (2007) Simultaneous RP-HPLC determination of nimesulide and tizanidine in tablets. Ind J Pharm Sci 69: 281283

6. Lakshmi SD (2009) Spectrophotometric and HPLC methods for Simultaneous estimation of Tizanidine and Valdecoxib from Tablets. Int J Chemtech Res 1 : 96-102.

7. Qi M, Wang P, Wang L (2003) Validated liquid chromatography method for assay of tizanidine in drug substance and formulated products. Anal Chimica Acta 478: 171-77.

8. Nirogi RV, Kandikere VN, Shukla M, Mudigonda K, Maurya S (2006) Quantification of tizanidine in human plasma by liquid chromatography coupled to tandem mass spectrometry. Rapid Commun Mass Spectrom 20: 2286-2292.

9. Chakravarty D, Charde RM, Charde MS, Tajne MR (2010) Estimation of Tizanidine HCl by UV-Spectrophotometric Method J Pharm Res 3: 2107-2109.

10. Hassounaa MEM, Adawib AM, Alib EA (2011) A simple kinetic spectrophotometric method for determination of Tizanidine hydrochloride in pharmaceutical preparations. Egyptian J Forensic Sci 1: 19-24.

11. Sujata JG, Mrunalini MD, Mahajan MP (2011) Simultaneous estimation of Tizanidine and Aceclofenac in bulk drug \& tablet formulation By Q-Analysis and Area under Curve. Int J Pharm Sci Rev Res 8: 58-61.

12. Gondane SJ, Deshpande MM, Mahajan MP, Sawant SD (2011) Spectrophotometric method development and validation for estimation of Tizanidine and Aceclofenac in Bulk Drug and Tablet formulation. Int $J$ Chemtech Res 3: 620-624.

13. Nallasivan PK, Saranya KC, Kumar RS, Jeevanantham RV (2010) Simultaneous determination of Ibuprofen and Tizanidine in bulk drug and its combined dosage form by spectrophotometry. Der Pharmacia Lettre 2: 289-295.

14. Rao KKV, Kumar SM, Mathivanan N, Kumar KM, Rao MEB (2004) Development and validation of spectrophotometric methods for the estimation of Tizanidine. Indian Drugs 4: 583

15. Narala SR, Saraswathi K (2011) Development and Validation of Spectrophotometric methods for the Estimation of Mesalamine in Pharmaceutical Preparations. J Chem Pharm Res 3: 784-787.

16. Majumder M, Gopinath B, Koni G, Singh SK (2009) New Spectrophotometric Determination of Tinofovir in Bulk and Pharmaceutical Dosage Form. E-J Chem 6: 537-540.

17. Ramesh PG, Basavaiah K, Prasad NR (2010) Sensitive and selective spectrophotometric assay of doxycycline hyclate in pharmaceuticals using Folin-Ciocalteu reagent. Acta Pharm 60: 445-454.

18. Siddappa K, Metre M, Reddy T, Tambe M, Gavanna M (2009) Sensitive Spectrophotometric methods for quantitative determination of hydralazine hydrochloride in pure and pharmaceutical formulation. World J Chem 4: 15-20.

19. Singh DK, Srivastava B, Sahu A (2003) Spectrophotometric determination of ajmaline and brucine by Folin Ciocalteu's reagent. J Serb Chem Soc 68: 685690

20. Patel B, Patel J, Parmar K, Patel M (2011) Spectrophotometric estimation of fourth generation Cephalosporin: Cefepime in pharmaceutical dosage forms IJPI's J Anal Chem 1: 7-11.

21. Gandhimathi M, Ravi TK (2008) Use of Folin-Ciocalteu phenol reagent and 3-methyl-2-benzothiazolinone hydrazine hydrochloride in the determination of oxcarbazepine in pharmaceuticals. Acta Pharm 58: 111-118. 
Citation: Rathee P, Dua K, Rathee S, Kumar V (2014) Statistical Design for Optimization and Determination of Tizanidine Hcl using FolinCiocalteu (Fc) as Chromogenic Reagent. Pharm Anal Acta 5: 307. doi:10.4172/2153-2435.1000307

Page 5 of 5

22. Folin O, Ciocalteu D (1927) Tyrosine and tryptophane determinations in proteins. J Biol Chem 73: 627-650.

23. Ikawa M, Schaper TD, Dollard CA, Sasner JJ (2003) Utilization of FolinCiocalteu phenol reagent for the detection of certain nitrogen compounds. J Agric Food Chem 51: 1811-1815.
24. Lowry OH, Rosebrough NJ, Farr AL, Randall RJ (1951) Protein measurement with the Folin phenol reagent. J Biol Chem 193: 265-275

25. Vinson JA, Zubik L, Bose P, Samman N, Proch J (2005) Dried fruits: excellent in vitro and in vivo antioxidants. J Am Coll Nutr 24: 44-50. 